\title{
Khat chewing practice and its perceived health effects among communities of Dera Woreda, Amhara region, Ethiopia
}

\author{
Asmamaw Zeleke ${ }^{1}$, Worku Awoke ${ }^{2 *}$, Endalew Gebeyehu' ${ }^{2}$, Fentie Ambaw ${ }^{2}$ \\ ${ }^{1}$ Food, Medicine and Health Care Administration and Control Authority (FMHACA) of Ethiopia, North Western Branch Office, \\ Bahir Dar, Ethiopia \\ ${ }^{2}$ College of Medicine and Health Sciences, Bahir Dar University, Bahir Dar, Ethiopia \\ Email: ${ }^{*}$ Workuawo@yahoo.com
}

Received 23 July 2013; revised 23 August 2013; accepted 30 August 2013

Copyright (C) 2013 Asmamaw Zeleke et al. This is an open access article distributed under the Creative Commons Attribution License, which permits unrestricted use, distribution, and reproduction in any medium, provided the original work is properly cited.

\begin{abstract}
Introduction: Khat chewing is believed to be rapidly increasing worldwide. Worldwide, it is estimated that 10 million people consume khat daily. Khat chewing practice renders certain influence on physical and psychological well being of the community and it can cause more serious adverse psychiatric, cardiovascular, dental and gastrointestinal effects. The recent sharp increase in khat consumption may not only affect the health of individuals but could also have serious socio-economic consequences. This study was conducted to assess prevalence of khat chewing practice, its associated factors and perceived health effects among communities in Dera woreda, Amhara region, Ethiopia 2013. Methods: Community-based cross-sectional study was conducted by using both quantitative and qualitative method of data. The sample size for quantitative was determined by using single population proportion formula and the households were selected by systematic sampling method and in the selected household, one respondent was selected by lottery among members of household aged 15 years and above. Data were collected by means of a pretested questionnaire; analysis was carried out using SPSS version 16. For the qualitative part ten in-depth interviews were conducted on purposely selected individuals and sample size for this method was determined through continuing to interview participants until no new information was obtained. Results: The response rate was $98.3 \%$. Current prevalence of khat chewing practice was $17 \%$. Males were more likely to chew khat (AOR, 18.53; 95\%CI, 7.20 - 47.66) compared to females. Muslims
\end{abstract}

"Corresponding author. were more likely to chew khat (AOR, 4.34; 95\%CI, 2.07 - 9.11) compared to Orthodox Christians. Respondents who had family member chewing khat were more likely to chew khat (AOR, 2.67; 95\%CI, 1.15 6.21) compared to family member without a chewer. Among all the respondents, 92.8\% perceived the health effects of khat chewing practice. Respondents who did not perceive health effect of khat were 5 times more likely to chew khat $(A O R=5.10,95 \% C I ; 1.64-15.5)$ compared to those who perceived health effect of khat. Conclusions: The prevalence of khat chewing practice was $17 \%$ with high proportion of the khat chewers found in the urban setting. Sex, religion, residence, family chewing habit and perceived health effect were significantly associated factors with khat chewing practice. In this study $92.8 \%$ of the respondents perceived that khat chewing practice had harmful effects on health and the perceived health effects reported were sleeping disorder, hallucination, tooth staining, anxiety, and loss of appetite, depression, constipation, gastritis, hypertension and psychosis.

Keywords: Khat Chewing; Perceived Health Effect; Ethiopia

\section{INTRODUCTION}

Khat (Catha edulis) is evergreen plant that contains psychoactive substances, cathinone and cathine, which produce central stimulation analogues to amphetamine [1]. There are several names for the plant, depending on its origin: chat, qat, qaad, jaad, miraa. In most literature, it is referred to as khat. Commonly it is known as "chat" in Ethiopia [2]. 
Khat chewing practice is believed to be rapidly increasing worldwide [3]. Worldwide, it is estimated that 10 million people consume khat daily [4].

Khat is harvested throughout the year and grows mainly in countries bordering the Red Sea and along the east coast of Africa including Ethiopia, Kenya, Yemen, Somalia, Sudan, South Africa and Madagascar. Ethiopia is thought to be the country of origin of khat use [5]. Ethiopia is the world's largest producer of khat, which is the country's fastest growing export. About a third of the production is exported to Djibouti and Somalia, but the bulk of it is marketed and consumed within the country [6]. Previously, khat was mainly cultivated in the eastern part of Ethiopia. Nowadays, it is grown in most parts of the country [7]. It grows at high altitudes of $1500-2500$ meters [8].

Habitual khat chewing renders certain influence on the physical and psychological well being of the community $[9,10]$ and it can cause more serious psychiatric, cardiovascular, dental and gastrointestinal adverse effects [11]. During khat chewing session, initially there is atmosphere of cheerfulness, optimism and a general sense of wellbeing. After khat chewing cessation, the individuals perceive some health problems where tension, emotional instability and irritability begin to appear, later leading to feelings of depression, confusion, insomnia and sluggishness. Different studies evidenced that psychological impacts of chewing khat are hazardous both to the individual and the community. Gastrointestinal adverse effects of khat chewing include anorexia, constipation and stomatitis. Anorexia leads to malnutrition and increased susceptibility to infectious diseases, especially tuberculosis $[12,13]$.

The recent sharp increase in khat consumption may not only affect the health of individuals but could also have serious socio-economic consequences for the countries involved in khat consumption. Khat chewing practice leads to loss of working hours, decrease of economic production and incurrence of a direct cost to Khat by neglecting family needs, leading to family discord and divorce and increasing likelihood to commit crimes. This is indirectly linked to absenteeism and unemployment, which may in turn result in a fall in overall national economic productivity $[14,15]$.

This study was conducted to assess prevalence of khat chewing practice, its associated factors and perceived health effects among communities in Dera woreda, Amhara region, Ethiopia 2013.

\section{METHODS}

\subsection{Study Design}

A community based cross-sectional study was conducted by using both quantitative and qualitative methods among people aged 15 years and above who lived for at least 6 months in Dera Woreda, Ethiopia from February to March 2013. Dera woreda is one of the Woredas in South Gondar zone, Amhara national regional state, Ethiopia.

The sample size for quantitative data was determined by using single population formula by considering, $95 \%$ CI, $5 \%$ of margin of error and $50 \%$ of proportion of khat chewing practice which was reported from previous studies done in Ethiopia [2]. Then, adding 10\% non-response rate, and since the study was a multistage sampling technique after adjusting for the design effect by a factor of 1.5 , the final sample size was calculated to be 633 . The households were selected by systematic sampling method and in the selected household one respondent was selected by lottery among members of household aged 15 years and above.

To supplement the quantitative data by qualitative method, ten in-depth interviews were conducted on purposely selected individuals and the sample size for the qualitative part was determined through continuing to interview participants until no new information was obtained. The purposeful selection of study participants were guided by certain criteria's mainly the experience of khat chewing habit from both males and females living in the study area.

\subsection{Data Collection and Data Analysis}

A structured questionnaire was initially developed in English and then translated into Amharic and then back to English before data collection for checking the consistency of translation. The Amharic version was used during data collection.

For the quantitative method, eight data collectors who completed grade 10 and two supervisors who completed grade 12 were involved, and training was given; mainly on the purpose of the study, handling ethical issues and method of data collection. The questionnaire was pretested prior to data collection and corrections were made accordingly. For consistency and completeness, the collected data were checked on a daily basis by supervisors. The collected data were coded, entered, cleaned, and analyzed using SPSS version 16. Bivariate analysis was done to examine associations between the dependent variable and each independent factor. Based on the bivariate analysis significantly associated factors were entered into multiple logistic regressions to get adjusted odd ratio. The strength of association was determined using crude odds ratio in the bivariate analysis and adjusted odds ratio in multivariate analysis. P-values and $95 \%$ confidence interval were used to determine level of significance of association. $P<0.05$ was considered statistically significant.

For the qualitative part, the principal investigator con- 
ducted the in-depth interview. Credibility of a quailtative study was preserved by reflectivity and avoiding objectivity. Data recorded by tape recorder from ten purposely selected individuals was transcribed word-by-word into plain text, and translated into English. After codes were developed, all the issues discussed under those codes were identified as themes. Finally, the identified themes were arranged into coherent groupings and reported.

\subsection{Ethical Considerations}

The research topic and methodology were approved by ethical committee of Bahir Dar University. Permission to conduct the study was also obtained from Amhara Regional State Health Bureau and Dera Woreda Health Office. Data collection was conducted, after explaining the aim of the study, confidentiality and its possible benefits to the study participant. Verbal informed consent was given with full information including purpose of the study, selection criteria, confidentiality, the right to stop the interview any time and benefit of the study. The interview was conducted after obtaining verbal consent from the study participant.

\section{RESULTS}

\subsection{Socio-Demographic Characteristics of the Respondents}

It was planned to collect data from 633 study participants and finally complete data were collected from 622 (98.3\%). The questionnaires of 11 respondents were rejected during data cleaning because of their incompleteness. Of the respondents, $201(32.3 \%)$ were found within the age group of $15-24$ years. The majority, $404(65 \%)$ were males, $516(83 \%)$ were Orthodox Christians, 416 (66.9\%) were married, $266(42.8 \%)$ were illiterate, 363 (58.4\%) were farmers, $413(66.4 \%)$ were rural residents (Table 1).

\subsection{Prevalence of Khat Chewing Practice}

It was found that 124 (19.9\%) of the respondents chewed khat at least once in their life time (ever khat chewers). Among the ever khat chewers 18 (14.5\%) stopped khat chewing practice. Among all respondents 106 (17\%) were chewing khat in the past one month at the time of the study (current khat chewers).

\subsection{Initiators to Start Khat Chewing Practice}

Multiple responses were obtained as reasons that initiated khat chewers for the first time to start khat chewing practice. Majority $55(51.9 \%)$ of the current khat chewers responded that peer pressure initiated them for the first time to start khat chewing practice (Table 2).
Table 1. Socio-demographic characteristics of respondents, among communities of Dera Woreda, March $2013(\mathrm{n}=622)$.

\begin{tabular}{|c|c|c|}
\hline Variables & Frequency & Percent \\
\hline \multicolumn{3}{|l|}{ Sex } \\
\hline Male & 404 & 65 \\
\hline Female & 218 & 35 \\
\hline \multicolumn{3}{|l|}{ Age } \\
\hline $15-24$ & 201 & 32.3 \\
\hline $25-34$ & 195 & 31.3 \\
\hline $35-44$ & 133 & 21.4 \\
\hline$>44$ & 93 & 15 \\
\hline \multicolumn{3}{|l|}{ Religion } \\
\hline Orthodox & 516 & 83 \\
\hline Muslim & 106 & 17 \\
\hline \multicolumn{3}{|l|}{ Marital status } \\
\hline Married & 416 & 66.9 \\
\hline Single & 185 & 29.7 \\
\hline Divorce/widowed & 21 & 3.4 \\
\hline \multicolumn{3}{|l|}{ Educational level } \\
\hline Illiterate & 266 & 42.8 \\
\hline Read and write & 107 & 17.2 \\
\hline Primary school $(1-8)$ & 161 & 25.9 \\
\hline Secondary school $(9-12)$ or above & 88 & 14.1 \\
\hline \multicolumn{3}{|l|}{ Occupation } \\
\hline Farmer & 363 & 58.4 \\
\hline Housewife & 31 & 5 \\
\hline Merchant & 85 & 13.7 \\
\hline Employee & 21 & 3.4 \\
\hline Student & 58 & 9.3 \\
\hline Job seeker & 34 & 5.5 \\
\hline Others $^{* *}$ & 30 & 4.8 \\
\hline \multicolumn{3}{|l|}{ Income } \\
\hline$<500$ & 330 & 53 \\
\hline $500-1000$ & 179 & 28.8 \\
\hline$>1000$ & 113 & 18.2 \\
\hline
\end{tabular}

***arber, driver, weaver, shoemaker, wood worker.

\subsection{Reasons for Khat Chewing Practice}

Multiple response reasons were obtained for khat chewing among respondents who already started khat chewing. 
The reasons reported for khat chewing among khat chewers in this study were; $48(45.5 \%)$ to be alert, 38 (35.8\%) for praying, $29(27.4 \%)$ to enjoy, $16(15.1 \%)$ to get concentration and other reasons like to kill time, not to be separated from friend, to reduce physical fatigue and to get energy.

\subsection{Perceived Health Effects of Khat Chewing Practice}

The majority, 577 (92.8\%) of respondents perceived that khat chewing practice could lead to health effects. Sleeping disorder was the most frequently perceived health effect followed by hallucination and tooth staining (Figure 1).

The qualitative part of this study supported results in Figure 1 and accordingly sleeping disorder and hallucination were repeatedly explored as negative health effects of khat chewing practice. A 27-year-old male orthodox respondent perceived that khat chewing practice cause mental illness and sleeping disorder and explained as follow, "Khat chewers become mentally ill. Khat chewers hallucinated during khat chewing practice. After they chewed, it makes them difficult to sleep. Since the khat harms their body and their brain, they usually be-

Table 2. Initiators for khat chewing practice in communities of Dera Woreda, March $2013(\mathrm{n}=622)$.

\begin{tabular}{ccc}
\hline Initiators for khat chewing practice & Frequency & Percent \\
\hline Peer pressure & 55 & 51.9 \\
Family chewing habit & 35 & 33 \\
Religion purpose & 26 & 24.5 \\
Production of khat & 24 & 22.6 \\
Academic purpose & 13 & 12.3 \\
Unemployment & 8 & 7.5 \\
Availability of room for chewing & 7 & 6.6 \\
\hline
\end{tabular}

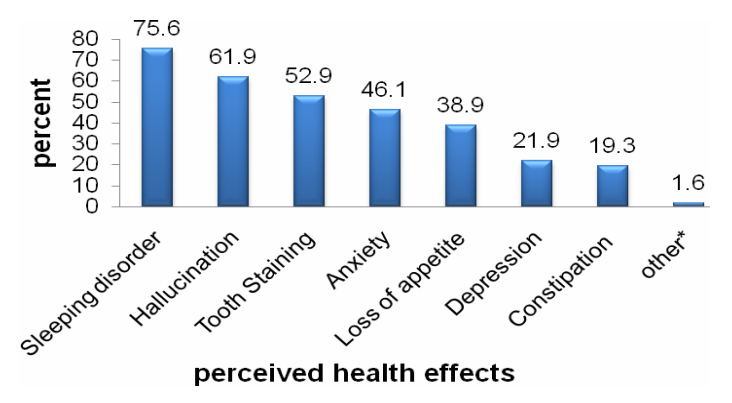

Figure 1. Perceived health effects reported by the respondents among communities of Dera woreda, March 2013; ' Gastritis, hypertension, psychosis; N.B. Due to possibility of multiple responses the total percentages does not add up to $100 \%$. come depressed." A 35-year-old male orthodox respondent also said, "Khat stimulates brain and increase blood circulation and cause hypertension. As to my experience during khat chewing I become hallucinated and after khat chewing I could not sleep unless I take 'chebsi' (localy prepared alcoholic drinks such as 'Tela and Araqe')."

Another 20-year-old male Muslim respondent explained that khat chewing practice cause sleeping disorder and hallucination and he said, "As to my experience during khat chewing I wish to make buildings and also wish to make things that I do not normally imagine but such things disappear the next day. And after khat chewing depression happened. Then I need 'Chebsi' (Alcohol 'Tela', 'Araqi', beer) to sleep otherwise I could not sleep. Khat chewing practice causes appetite loss too."

One 48-year-old male Orthodox Christian respondent also confirmed that sleeping disorder and hallucination as the negative health effect of khat chewing practice and said, "During khat chewing, just it makes me wish what I don't have and it makes me feel peace and makes me think positive things for other persons. When I finish khat chewing I need to sleep but I could not sleep unless I took chebsi' (alcoholic drinks). In addition, now I had highly developed gastritis due to khat chewing practice."

\subsection{Factors Associated with Khat Chewing Practice}

Bivariate analysis was done to establish statistical significance and strength of association between each factor and dependent variable/khat chewing practice/. All factors which were significant during the bivariate analysis (sex, age, religion, marital status, educational level, occupation, residence, family chewing habit, production of khat in residence, being khat producer and perceived health effect) were entered into multiple logistic regression for multivariate analysis. The significant predictors of khat chewing practice during the multivariate analysis at $\mathrm{p} \leq$ 0.05 were sex, religion, residence and family chewing habit and perceived health effect.

Males were 18 times more likely to chew khat $(\mathrm{AOR}=$ 18.53 ; 95\%CI; 7.20 - 47.66) compared to females. Muslims were 4 times more likely to chew khat (AOR $=4.34$, 95\%CI; 2.07 - 9.11) compared to orthodox Christians. Respondents who had family member chewing khat were 2.7 times more likely to chew khat $(\mathrm{AOR}=2.67,95 \% \mathrm{CI}$; 1.15 - 6.21) compared to those who did not have a chewer family member. Respondents who did not perceive that khat chewing had health effect were 5 times more likely to chew khat $(\mathrm{AOR}=5.10,95 \% \mathrm{CI} ; 1.64$ 15.5) compared to those who perceived khat chewing had health effect (Table 3). 
Table 3. Factors associated with khat chewing practice practice in communities of Dera Woreda, March 2013.

\begin{tabular}{|c|c|c|c|c|}
\hline \multirow[t]{2}{*}{ Variables } & \multirow[t]{2}{*}{ Khat chewers $(\mathrm{n}=106)$} & \multirow[t]{2}{*}{ Non khat chewers $(\mathrm{N}=516)$} & \multicolumn{2}{|c|}{$\mathrm{OR}(95 \% \mathrm{CI})$} \\
\hline & & & Crude & Adjusted \\
\hline \multicolumn{5}{|l|}{ Sex } \\
\hline Male & 94 & 310 & $5.21(2.78-9.74)$ & $18.53(7.2-47.66)^{*}$ \\
\hline Female & 12 & 206 & 1.0 & 1.0 \\
\hline \multicolumn{5}{|l|}{ Age } \\
\hline $15-24$ & 28 & 173 & 1.0 & 1.0 \\
\hline $25-34$ & 32 & 163 & $1.21(0.70-2.10)$ & $0.99(0.38-2.61)$ \\
\hline $35-44$ & 23 & 110 & $1.29(0.71-2.36)$ & $2.55(0.69-9.35)$ \\
\hline$>44$ & 23 & 70 & $2.03(1.10-3.76)$ & $1.15(0.27-4.99)$ \\
\hline \multicolumn{5}{|l|}{ Religion } \\
\hline Orthodox & 35 & 481 & 1.0 & 1.0 \\
\hline Muslim & 71 & 35 & $27.88(16.4-47.4)$ & $4.34(2.07-9.11)^{*}$ \\
\hline \multicolumn{5}{|l|}{ Marital status } \\
\hline Married & 59 & 357 & 1.0 & 1.0 \\
\hline Single & 40 & 145 & $1.67(1.07-2.61)$ & $1.26(0.47-3.40)$ \\
\hline Divorce/widowed & 7 & 14 & $3.03(1.17-7.81)$ & $2.89(0.47-17.88)$ \\
\hline \multicolumn{5}{|l|}{ Educational level } \\
\hline Illiterate & 18 & 248 & 1.0 & 1.0 \\
\hline Read and write & 12 & 95 & $1.74(0.80-3.75)$ & $0.99(0.23-4.21)$ \\
\hline Primary school $(1-8)$ & 45 & 116 & $5.35(2.97-9.64)$ & $1.24(0.39-3.94)$ \\
\hline Secondary school $(9-12)$ or above & 31 & 57 & $7.50(3.92-14.33)$ & $1.36(0.36-5.09)$ \\
\hline \multicolumn{5}{|l|}{ Occupation } \\
\hline Student & 7 & 51 & 1.0 & 1.0 \\
\hline Farmer and housewife & 5 & 389 & $0.09(0.03-0.31)$ & $5.32(0.59-48.10)$ \\
\hline Merchant & 50 & 35 & $10.41(4.23-25.61)$ & $5.50(1.23-24.47)^{*}$ \\
\hline Employee & 12 & 9 & $9.71(3.01-31.33)$ & $4.50(0.79-25.54)$ \\
\hline Job seeker & 14 & 20 & $5.10(1.80-14.50)$ & $2.16(0.48-9.80)$ \\
\hline Others & 18 & 12 & $10.93(10.93-3.73)$ & $2.15(0.39-11.59)$ \\
\hline \multicolumn{5}{|l|}{ Family chewing habit } \\
\hline Yes & 38 & 20 & $13.86(7.62-25.20)$ & $2.67(1.15-6.21)^{*}$ \\
\hline No & 68 & 496 & 1.0 & 1.0 \\
\hline \multicolumn{5}{|l|}{ Production of khat in residence } \\
\hline Yes & 30 & 452 & 1.0 & 1.0 \\
\hline No & 76 & 64 & $17.90(10.9-29.4)$ & $1.75(0.76-4.10)$ \\
\hline \multicolumn{5}{|l|}{ Being khat producer } \\
\hline Yes & 4 & 361 & 1.0 & 1.0 \\
\hline No & 102 & 155 & $59.40(21.5-164.1)$ & $0.93(0.11-8.1)$ \\
\hline \multicolumn{5}{|l|}{ Perceived health effect } \\
\hline Yes & 81 & 496 & 1.0 & 1.0 \\
\hline No & 25 & 20 & $7.70(4.10-14.4)$ & $5.10(1.64-15.5)^{*}$ \\
\hline
\end{tabular}

*Statistically significant at $\mathrm{P} \leq 0.05$. 


\subsection{Displaying of Themes in the In-Depth Interview}

In this study, themes, categories and codes were developed from the in-depth interview based on the objective of the study (Table 4).

\section{DISCUSSIONS}

This study found that prevalence of ever khat chewing practice was $19.9 \%$ and current prevalence of khat chewing practice was $17 \%$. The current prevalence of khat chewing practice in this study was lower than that of community based studies in Butajira in 1995 with $50 \%$ [2], Jimma town in 2000 with $30.6 \%$ [10], Adamitulu in 1997 with $31.7 \%$ current prevalence [16]. The lower prevalence of khat chewing practice than the present ones might be explained by relatively higher cultural unacceptance of the khat chewing habit and greater proportion of orthodox Christians who condemn khat chewing practice mainly in the rural area.

This study revealed peer pressure, family chewing habit, religion purpose and production of khat in residence were main reasons that initiated khat chewers to begin khat chewing for the first time. The reasons reported for chewing khat among khat chewers in this study were to stay alert, to enjoy, getting concentration, to pray, and other reasons like to kill time, to reduce physical fatigue

Table 4. Displaying themes, categories and codes as identified from the qualitative data in Dera Woreda, March 2013.

\begin{tabular}{|c|c|c|}
\hline Theme & Category & Code \\
\hline \multirow[t]{5}{*}{$\begin{array}{l}\text { Reasons to } \\
\text { chew khat }\end{array}$} & Peer pressure & $\begin{array}{c}\text { Friends who are khat chewer } \\
\text { initiated you to chew khat. } \\
\text { Tell you chewing khat makes } \\
\text { you enjoy and alert }\end{array}$ \\
\hline & Religion purpose & $\begin{array}{c}\text { Prevent sleeping and to be alert } \\
\text { and be concentrate during } \\
\text { preying to Alaha (diwa) }\end{array}$ \\
\hline & Enjoyment & $\begin{array}{l}\text { Chewed for recreation and } \\
\text { makes you enjoy and excite }\end{array}$ \\
\hline & Alertness & $\begin{array}{c}\text { Avoid depression and makes to } \\
\text { do work quickly }\end{array}$ \\
\hline & Energy & Avoid fatigue during working \\
\hline \multirow[t]{5}{*}{$\begin{array}{l}\text { Perceived } \\
\text { health effects } \\
\text { of khat }\end{array}$} & Hallucination & $\begin{array}{l}\text { Wish to make } \\
\text { unimaginary things }\end{array}$ \\
\hline & Sleep disorder & $\begin{array}{l}\text { Could not sleep unless drink } \\
\text { alcohols "Chebsi" }\end{array}$ \\
\hline & Gastric problem & Developed gastritis \\
\hline & Hypertension & $\begin{array}{l}\text { Stimulates brain and } \\
\text { increase blood circulation }\end{array}$ \\
\hline & $\begin{array}{l}\text { Other perceived } \\
\text { health effects }\end{array}$ & $\begin{array}{c}\text { Depression, anxiety, loss of } \\
\text { appetite }\end{array}$ \\
\hline
\end{tabular}

and to get relief from minor illness. These results were strengthened by the in-depth interview in this study. The respondents in the in-depth interview elaborated that they chewed khat to be alert, for enjoyment, and to avoid sleeping during praying. A 35-year male orthodox respondent from the in-depth interview said, "I chew khat to make myself excite, to be alert and for enjoyment." and a 48 years male orthodox respondent from the indepth interview said, "I chew khat to be alert during working." Another 57-year-old male Muslim respondent from the in-depth interview explained that he chewed khat to be alert and to avoid sleeping during praying he said, "I chew khat just to be alert and to get energy while I am working and to avoid sleeping during praying."

In this study khat chewing practice was found to be 18 times more likely among males as compared to females. This finding was consistent with community based study findings in Butajira in 1995 [2], Adamitulu in 1997 [16] and Jima town in 2000 [10], Kampala district, Uganda in 2011 [3]. This might be because females are more culturally restricted from exposure to khat chewing practice [10].

In this study khat chewing practice was found to be 4 times more likely among Muslims as compared to orthodox Christians. This finding was in line with community based studies reported for Butajira in 1995 [2], for Adamitulu in 1997 [16], Jimma town in 2000 [10]. The community based study in Makindye division (Uganda) also indicated Muslims were more likely to chew khat $(\mathrm{OR}=3.8,95 \% \mathrm{CI} ; 1.28-1.44)$ compared to Christians [3]. The possible reason for the observed higher prevalence of khat chewing practice among Muslims, this could due to traditionally common habit of chewing and chewing interest to gain maximum concentration during praying time in Muslim population [6,17] although there were few Muslims in the community who condemn khat chewing practice and said not culturally accepted.

This was also supported by the qualitative finding and A 27-year-old male respondent from the in-depth interview explained that Muslims chew khat during praying and he said that, "Muslims chew khat during praying."

A 57-year-old male Muslim respondent from the indepth interview explained that Muslims chew khat to be alert and to avoid sleeping during praying and he said, "Muslim religion do not allow khat chewing practice but khat is frequently chewed by Muslims to prevent sleeping and to be alert during praying and I chew khat just to be alert and to get energy while I am working and to avoid sleeping during praying."

Another 20-year-old male Muslim respondent also explained that Muslims chew khat to avoid sleeping during praying to Alaha and he said, "It is thought that khat is allowed for Muslim but khat is not allowed for Muslims. Muslims chew khat just to be alert and aviod sleep- 
ing during praying but currently Christians are also commonly chewing khat."

The findings that Muslims were more khat chewers compared to other religion followers did not conform to some other studies. For instance in Saud Arabia, khat chewing is discouraged because it has no foundation in Islam $[3,18]$.

In this study only $1(0.2 \%)$ respondent was found to be rural resident and the majority of khat chewers 105 (50.2\%) were urban residents and this implied that almost no khat chewers in rural areas. This finding was inconsistent with the study done in rural communities of Butajira, Ethiopia in 1995 which found that the prevalence of khat chewing practice in the rural area was $50 \%$ but the explanation given for such increased prevalence in rural communities of Butajira was Muslim population predominates as rural residents and Khat growing and the practice of chewing khat has traditionally been confined to the Muslim population [2]. Unlike the study in Butajira, in this study khat growing practice was more common among orthodox Christians than Muslims. In addition, this study participants there were no Muslim rural residents and all the rural residents 413 (100\%) were Orthodox Christians and khat chewing practice is not acceptable culturally as well as by religion (Orthodox Christians) in the rural area.

Khat chewing practice was found to be 2.7 times more likely among respondents who had a family member chewing khat as compared to khat chewers who did not have anyone in their family chewing khat. This finding was in line with what was found in a community based study conducted in Makindye division, Uganda where, respondents who had a family member chewing khat, $71.1 \%$ were khat chewers $(\mathrm{AOR}=2.1,95 \% \mathrm{CI} ; 1.10$ 3.92 ) compared to $53 \%$ khat chewers who did not have anyone in their family chewing khat [3]. This might be because living in a family where parents chew khat could initiate the family members to chew khat.

Majority of respondents $482(77.5 \%)$ said that khat was produced in their residence but only $30(6.2 \%)$ of them were khat chewers and the association between production of khat in residence and khat chewing practice were not statistically significant $(p=0.191)$. This insignificance might be majority of respondents were living in rural area but khat chewing practice might not be common among the rural residents though khat is mainly produced in rural area.

Majority of the respondents 365 (58.7\%) were khat producers and among khat producers only $4(1.1 \%)$ were khat chewers and the association between being khat producer and khat chewing practice was not statistically significant $(\mathrm{p}=0.949)$. This might be explained by khat was produced because its economic benefit was more than other cash crops and khat production predominates in rural areas where khat chewing practice not accepted by religion (being orthodox Christian) and culturally not accepted in rural residents of this study. This finding was inconsistent with community based study finding reported for Butajira in 1995 where khat chewing practice was common among khat producers [2]. The reasons might be religion variation in residence as discussed above under religion and residence factors.

About 577 (92.8\%) of the respondents in this study perceived that khat chewing practice could lead to negative health effect. In this study respondents who did not perceive health effect of khat chewing were 5 times more likely to chew khat $(\mathrm{AOR}=5.10,95 \% \mathrm{CI} ; 1.64-15.5)$ compared to those who perceived health effect khat chewing. This finding was in line with community based study done in Uganda in 2011 where it was found that awareness of the health effects of khat $(\mathrm{AOR}=0.3$; $95 \% \mathrm{CI} ; 0.15-0.54$ ) had been associated with decreased risk of khat chewing practice [3]. The perceived health effects of khat chewing practice reported in this study included sleeping disorder, hallucination, tooth staining, anxiety, loss of appetite, depression, constipation, and other health effects like gastritis, hypertension and psychosis. These results were consistent with community based study done in England in 2009 [19], Khat chewing among Somalis in four English cities [20] where hallucination, depression, sleeping disorder and anxiety were reported as perceived health effects of khat chewing practice. These results were also supported by the quailtative part of this study. Sleeping disorder, hallucination, gastritis, loss of appetite and depression were perceived health effects of khat chewing practice explored during the in-depth interview.

A 27-year-old male orthodox respondent perceived that khat chewing practice cause hallucination and sleeping disorder and explained as follow, "Khat chewers hallucinated during khat chewing practice. After they chewed, it makes them difficult to sleep. Since the khat harms their body and their brain, they usually become depressed."

A 48-year-old male orthodox respondent explained that sleeping disorder and hallucination as the negative health effect of khat chewing practice and he said, "To my experience khat chewing cause health effect on me and now I had highly developed gastritis due to khat chewing practice. During khat chewing practice, it makes me wish what I do not have and after khat chewing I could not sleep unless I take 'chebsi' (drink alcohols)."

A 20-year-old male Muslim respondent also confirmed that khat chewing practice cause sleeping disorder and hallucination and he said, "Khat chewing practice causes loss of appetite. As to my experience during khat chewing I wish to make buildings and also wish to make unimaginary things. After khat chewing practice depres- 
sion happened. Then I need 'Chebsi' (Alcohol drinks) to sleep otherwise I could not sleep."

This study indicated that marital status, educational level, income, occupation, production of khat in residence, and being khat producer were not predictors of khat chewing practice and their association with khat chewing practice was not statistically significant. Their insignificant association might be due to confounding factors.

\section{CONCLUSION}

The prevalence of khat chewing practice was $17 \%$ with high proportion of the khat chewers found in the urban setting. Sex, religion, residence, family chewing habit and perceived health effect were significantly associated factors with khat chewing practice and peer pressure was found to be the major reason that initiated individuals to begin khat chewing practice. In this study $92.8 \%$ of the respondents perceived that khat chewing practice had harmful effects on health and the perceived health effects reported were sleeping disorder, hallucination, tooth staining, anxiety, and loss of appetite, depression, constipation, gastritis, hypertension and psychosis.

\section{ACKNOWLEDGEMENTS}

We would like to thank Bahir Dar University, College of Medicine and Health Science. We are also grateful for the cooperation of the study participants, data collectors and supervisors.

\section{REFERENCES}

[1] Michael, O. (2007) Chronic khat use and psychotic disorders: A review of the literature and future prospects. Konstanzer Online-Publikations-System (KOPS). http://www.ub.uni-konstanz.de/kops/volltexte /2008/4059/

[2] Alem, A., Kebede, D. and Kullgren, G. (1999) The prevalence and socio-demographic correlates of khat chewing in Butajira, Ethiopia. Acta Psychiatrica Scandinavica, 100, 84-91.

http://dx.doi.org/10.1111/j.1600-0447.1999.tb10699.x

[3] Kasule, H. (2011) Prevalence, factors associated with and perceived health effects of use of cannabis/khat among persons aged 18 years and above in Makindye division, Kampala district. Uganda Makerere University.

[4] John Fitzgerald, L.L. (2009) Khat: A literature review. http://www.ceh.org.au/downloads/khat report final.pdf

[5] Glenice Cox, H.R. (2003) Adverse effects of khat: A review. Journal of Continuing Professional Development, 9, 456-463.

[6] Taye Hailu Feyisa, J.B.A. (2003) Khat expansion in the Ethiopian highlands: Effects on the farming system in Habro district. Mountain Research and Development, 23, 185-189.
http://dx.doi.org/10.1659/0276-4741(2003)023[0185:KEI TEH]2.0.CO;2

[7] (ECDD) WECoDD (2006) Assessment of khat (Catha edulis Forsk). WHO Expert Committee on Drug Dependence.

www.who.int/medicines/areas/quality safety/4.4 KhatCritReview.pdf

[8] Ahmed AL-Motarreb KbaK, J.B. (2002) Khat: Pharmacological and medical aspects and its social use in Yemen. Phytotherapy Research, 16, 403-413. http://dx.doi.org/10.1002/ptr.1106

[9] Abebe, D. et al. (2006) Is khat-chewing associated with HIV risk behaviour? A community-based study from Ethiopia. African Journal of AIDS Research, 5, 61-69.

[10] Andualem, M. (2002) The prevalence and socio- demographic characteristics of khat chewing in Jimma town, South Western Ethiopia. Ethiopian Journal of Health Science, 12, 69-80.

[11] Hussein, M. and Ageely, A. (2008) Health and socio-economic hazards associated with khat consumption. Journal of Family Community Medicine, 15, 3-11.

[12] Mekonnen, G. (2006) The prevalence of khat-induced psychotic reactions among college students: A case in Jimma University College of Agriculture. Ethiopian Journal of Education \& Science, 2, 1.

[13] Yigzaw, K. et al. (2005) Substance abuse for the Ethiopian health center team module. www.cartercenter.org/.../pdfs /health/.../Mod Substance Abuse final.pdf

[14] Melaku, B. et al. (2009) Prevalence, attitude and associated problems of khat use among Bahir Dar University Students, Northwestern Ethiopia. http://www.scribd.com/doc/39095347/Prevalence-Attitud e-and-Associated-Problems-of-Khat-Use

[15] Rashad, E. et al. (2011) Socio-medical problem of the habituation of khat chewing in Jazan region in Southern Saudi Arabia. European Journal of Scientific Research, 63, 122-133.

[16] Michael, O. (2006) The use of the stimulant khat, war-related trauma and psychosis in Somalia, University of Konstanz. http://kops.ub.uni-konstanz.de/volltexte/2009/8936

[17] Deborah, Z. (2008) Ethiopian social policy reader. http://groups.google.com/group/ethiopian-social-policy-r eader-2008

[18] Sikiru, L. (2012) Flower of paradise (Khat: Catha edulis): Psychosocial, health and sports perspectives. African Journal of Health Science, 22, 161-175.

[19] Wendy, S. et al. (2010) Perceptions of the social harms associated with khat use. https://www.gov.uk/government/uploads/system/uploads/ attachment data/file/116579/horr44-summary.pd

[20] Shilpa, L. et al. (2005) Khat use among Somalis in four English cities.

http://collection.europarchive.org/tna/20080205132101/h omeoffice.gov.uk/rds/pdfs05/rdsolr4705.pdf 


\section{LIST OF ABBREVIATIONS}

ANRS: Amhara National Regional state

AOR: Adjusted Odd Ratio

COR: Crude Odd Ratio

HH: Household

SPSS: Statistical Package for Social Sciences 